\title{
A Contação de história como estratégia para o ensino de ciências
}

Hugo Noronha da Silva Barros*, Ana Carolyne de Oliveira Cardoso**, Denise Ana Augusta dos Santos Oliveira ${ }^{\star \star *}$, Jorge Cardoso Messeder ${ }^{\star \star * *}$

\section{Resumo}

O artigo traz discussões sobre uma intervenção pedagógica, proposta em um projeto do Programa Institucional de Bolsas de Iniciação Científica (PIBIC), que objetivou promover uma associação entre histórias infantojuvenis e o ensino de ciências. As atividades foram baseadas no enfoque Ciência, Tecnologia e Sociedade (CTS), a partir de um estudo do tipo qualitativo, classificado como pesquisa-intervenção. O tema norteador da pesquisa se deu a partir de uma contação de história, para 23 crianças do $4^{\circ}$ ano do ensino fundamental da rede municipal do município de Duque de Caxias (RJ). Em seguida, foram desenvolvidas estratégias didáticas em sala de aula, promovendo a abordagem CTS, por meio das narrativas da literatura infantojuvenil, o que propiciou uma oficina de confecção de lunetas com discussões humanísticas e uma atividade que evidenciou riscos químicos de produtos saneantes domissanitários. Assim, a pesquisa possibilitou a exploração de novas perspectivas para a alfabetização científica das crianças dessa etapa da escolarização. Os resultados apontaram para as possibilidades de se aliar as histórias infantojuvenis e o ensino de ciências, promovendo discussões humanísticas e sociocientíficas, aproximando o saber científico ao mundo real.

Palavras-chave: Contação de história; Ensino de Ciências; Ensino Fundamental.

* Mestrando em Ciência e Tecnologia de Polímeros pelo Instituto de Macromoléculas (IMA/UFRJ). Licenciado em Química pelo Instituto Federal do Rio de Janeiro (IFRJ), Nilópolis, Rio de Janeiro, Brasil. E-mail: hugobarros2011@gmail.com

* Licencianda em Química pelo Instituto Federal do Rio de Janeiro (IFRJ), Nilópolis, Rio de Janeiro, Brasil. E-mail: karolyne_n10@hotmail.com

*** Doutoranda em Educação em Ciências e Saúde pelo NUTES/UFRJ. Mestre em Ensino de Ciências pelo Instituto Federal do Rio de Janeiro (PROPEC/IFRJ). Professora dos anos iniciais do Ensino Fundamental na rede Municipal de Educação de Duque de Caxias, Rio de Janeiro, Brasil. E-mail: prof.deniseana@gmail.com

**** Doutor em Ciências pelo Instituto Militar de Engenharia (IME). Professor do Curso de Licenciatura em Química e do Programa de Pós-graduação em Ensino de Ciências do Instituto Federal do Rio de Janeiro (PROPEC/ IFRJ), Nilópolis, Rio de Janeiro, Brasil. E-mail: jorge.messeder@ifrj.edu.br

Recebido em: 05/07/2020 - Aceito em: 04/12/2020.

https://doi.org/10.5335/rbecm.v4i1.11281

http://creativecommons.org/licenses/by-nc-nd/4.0 


\section{Introdução}

A aproximação entre literatura infantil e ensino de ciências não é inédita nas pesquisas que vêm sendo realizadas, conforme apontam os trabalhos de Oliveira e Messeder (2017) e Roedel (2016). Contudo, o baixo volume de publicações limita explorar características únicas dessas atividades que podem influenciar no processo de ensino/aprendizagem do estudante. Atividades desse cunho tendem a explorar a leitura crítica no indivíduo, o que torna a compreensão mais aprofundada e permite que o estudante possa ir além do senso comum, com um pensar arguidor, para uma formação cidadã, uma vez que permite o desenvolvimento de competências para a tomada de decisão (SANTOS; SCHNETZLER, 1996).

O ensino nos anos iniciais do ensino fundamental necessita de atenção à criança nas reflexões amplas sobre Ciência e Tecnologia. Fabri e Silveira (2012) entendem que não é suficiente ensinar conceitos, mas é precisa que a criança, desde pequena, comece a refletir sobre o que ouve em seu contexto social. Utilizar a leitura literária para nortear as atividades no contexto em Ciência, Tecnologia e Sociedade (CTS) é bastante pertinente, uma vez que ajuda a desenvolver nas crianças o hábito de ler, que por si só já traz consigo muitos benefícios, como: desenvolver o senso crítico, exercitar a empatia, estimular a criatividade, a concentração, a oralidade e o vocabulário, dentre outros (ARANA; KLEBIS, 2015). Portanto, o hábito da leitura se faz uma ferramenta muito importante para o desenvolvimento cognitivo dos estudantes, em que possibilita entender o mundo e suas transformações.

Neste trabalho buscou-se a conexão entre a literatura infantojuvenil e abordagens sobre conhecimentos químicos, particularmente sobre os riscos químicos inerentes aos produtos domissanitários que comumente são encontrados em ambientes domésticos. Acreditamos que este tema apresenta potencial para promover o desenvolvimento de capacidades de pensamento crítico, já que através de produtos comuns ao cotidiano podem ajudar no entendimento do mundo real por parte da criança e do adolescente, em virtude dos conteúdos aprendidos na escola serem transpassados para a realidade tornando o aprendizado mais significativo (PIRES; DECCACHE-MAIA; MESSEDER, 2016). Portanto, conciliar tais atividades é muito importante para o desenvolvimento cognitivo dos estudantes, uma vez que, possibilitam entender o mundo e suas transformações de forma coerente e condizente com os conteúdos abordados em sala de aula. 
Considerando o ensino de ciências a partir de questões sociais, o presente trabalho aborda uma atividade de intervenção pedagógica, alicerçada nos estudos CTS, e que foi realizada por dois bolsistas do Programa Institucional de Bolsas de Iniciação Científica (PIBIC), juntamente com a professora regente de uma turma de $4^{\circ}$ ano do ensino fundamental (uma das autoras deste artigo). A contação de uma história infantojuvenil para os estudantes do $4^{\circ}$ ano foi norteadora para o desenvolvimento das estratégias didáticas expostas aqui, que possibilitaram a exploração de novas perspectivas para a alfabetização científica das crianças dessa etapa da escolarização. A intervenção pedagógica foi elaborada para despertar a imaginação das crianças, em função da história contada, e para alertar e instruí-las sobre os perigos envolvidos em utilizar ou armazenar de forma inadequada produtos domissanitários, amplamente presentes no cotidiano.

\section{A linguagem como forma de ser e entender}

A linguagem é de natureza intrínseca ao homem e se faz fundamental no desenvolvimento e na estruturação da vida em sociedade, assim afirma Silva (2016, p. 23), que a "linguagem, como sistema simbólico por excelência, é o elo intermediário homem-mundo e homem-homem". Dessa forma, para se fazer ciência é fundamental que o estudante domine e exercite a linguagem, estabelecendo um código claro e coerente para que se possa entender e construir conhecimentos entre os pares. Messias (2006) apresenta em sua dissertação alguns objetivos implícitos ao código da comunicação humana, em que tende ao compreender e fazer-se compreendido conectando as ideias explícitas e implícitas de modo interativo, a fim de promover uma interlocução ou uma análise crítica no decorrer de um texto. Ainda, segundo o autor: "isso significa que o indivíduo, ao utilizar a linguagem, não quer apenas transmitir informações ou exteriorizar seu pensamento, mas realiza ações por meio da linguagem e atua sobre o interlocutor, buscando interagir com ele e influenciá-lo" (MESSIAS, 2006, p. 10).

Intuitivamente para se atingir uma linguagem mais eloquente, se faz necessário adquirir conhecimentos pertinentes para que se possa alcançar maior domínio sobre o conteúdo abordado. Com isso, tem-se por conhecimento geral que para o melhor falar, é necessário ter uma grande vivência e/ou ter adquirido experiência através da leitura de bons textos. $\mathrm{O}$ ato de ler é muito mais do que a simples interpretação 
ou junção de vocábulos, uma vez que transcende por vezes a sequência de palavras e engloba um sentido mais amplo que fica subentendido no decorrer do texto.

Realizar uma leitura crítica permite ao leitor explorar e extrair o máximo de informações que o autor tenta passar, e dessa maneira entender as ideias explícitas, implícitas e suas conclusões frente ao tema, promovendo o compartilhamento de informações, a análise delas e o corolário por parte do leitor, assim sua capacidade interpretativa é desenvolvida face às informações apresentadas. O exercício dessa leitura crítica é uma tarefa que demanda tempo e dedicação, e é incentivada desde o início da escolarização (KOCH; ELIAS, 2006). Os documentos legais, como os Parâmetros Curriculares Nacionais (PCN) (BRASIL, 1997), e a atual Base Nacional Comum Curricular (BNCC) (BRASIL, 2017), trazem a importância do desenvolvimento deste tipo de atividade no decorrer do ensino básico. A literatura, explorada em suas diferentes tipologias de texto ficcional, aparece em todos os segmentos do ensino, e dessa forma, possibilita que se promova a formação cidadã no desenrolar do processo de escolarização.

Portanto, cabe à escola, desde os primeiros anos, preparar os estudantes para desenvolver um conjunto de habilidades que possibilitem ao discente um conhecimento emancipador frente ao seu cotidiano. Ao pensar nisto, é coerente que todo o corpo educacional se volte para a realidade vivenciada, e busque promover propostas que incentivem as crianças e os jovens na procura por saberes, e consequentemente um maior desenvolvimento cognitivo de cada um. Buscar textos que se adequem a estrutura cognitiva do estudante é natural e imprescindível, pois estes devem ter apelo do público-alvo tornando-o mais interessado pela história contada, de modo a promover maior interação. Com isso, escolheu-se, na presente pesquisa, uma literatura infantojuvenil que pudesse ser trabalhada com alunos na faixa etária de 8 a 12 anos.

\section{Reflexões por trás da literatura infantojuvenil}

A literatura infantojuvenil é riquíssima, e traz um grande número de aventuras e descobertas, o que possibilita viajar por mundos encantados, conhecer princesas e reinos, lutar contra monstros, assim como encontrar e usar objetos mágicos e tesouros. Isso porque seu público-alvo tem grande apelo por histórias fantasiosas que exploram a imaginação, de fácil interpretação e de rápido desfecho, devido a sua capacidade cognitiva ainda estar em desenvolvimento. Blanco, Silva e Sobies- 
zczanski (2015), afirmam que nessa fase a criança ainda tende a enxergar o mundo como se fosse uma animação, no qual ela se permite dar vida a objetos inanimados, tornando mais fácil estabelecer uma comunicação a partir da linguagem lúdica.

Incentivar a leitura nos anos iniciais de ensino é muito importante para aguçar a curiosidade e a capacidade em resolver problemas, pois por mais que para nós, adultos, as histórias pareçam de fácil dedução, e por vezes simplistas, para as crianças, apresentam uma linha de raciocínio desconhecida que com o passar da história vai sendo descoberta até seu desfecho final, o que poderia ser comparado a um jogo de quebra-cabeça, em que pequenas partes da história vão se juntando e formam uma grande imagem que é o seu desenredo (BRANDÃO; ROSA, 2011).

Neste trabalho, utilizou-se o livro nacional "A Luneta Mágica no Reino da Escuridão" (QUEIROZ, 2016) cuja autora é também contadora de histórias. O livro possui características fundamentais para uma boa história infantojuvenil, em que vale citar: um enredo de fácil entendimento e não muito alongado, belas ilustrações, mistérios no decorrer da história, e um desfecho positivo e romantizado.

\section{Compreender e fazer ciência: uma responsabilidade social}

De acordo com Chassot (2003), a ciência pode ser entendida como a tentativa em se explicar o mundo natural, elaborando um conjunto de conhecimentos de maneira ordenada, a fim de descrevê-lo cientificamente, logo, alfabetização científica é possibilitar o entendimento e a leitura dessa linguagem. Assim como Chassot definiu o termo alfabetização científica, outros autores apuraram sobre o tema (SASSERON; CARVALHO, 2011; LORENZETTI; DELIZOICOV, 2001; TEIXEIRA, 2013) chegando a definições singulares que apresentam em si convergências.

Saber descrever o ambiente pelos olhos da ciência não é algo fácil e nem trivial, uma vez que o simples fato de só observar, por vezes não lhe garante o entendimento completo de certo evento, e logo se faz necessário utilizar da curiosidade e da imaginação para tentar propor uma explicação plausível da realidade. Dessa forma, para que se possa construir uma educação científica, é necessário que se tenha um pensamento e método científico, que no geral consiste em: observar o problema, propor uma explicação para o problema, analisar os dados do processo e formular uma conclusão (ZÔMPERO; LÁBURU, 2011). 
A educação científica torna-se importante para a sociedade, uma vez que indivíduos conscientes das suas decisões sobre o impacto das ciências e tecnologias nas relações sociais e ambientais são condicionados a terem um posicionamento crítico frente às informações sobre tais temas (MUNDIM; SANTOS, 2012). Deste modo, a escola tem o papel de proporcionar aos alunos condições de compreenderem a relação da sociedade com as ciências e as tecnologias. Segundo Sasseron e Carvalho (2008), o ensino fundamental é um momento oportuno para tratar de relações com CTS, a fim de promover a alfabetização científica.

Trazer temas CTS para se trabalhar a alfabetização científica no ensino fundamental, é uma estratégia importante e que vem produzindo bons frutos (SASSERON; CARVALHO, 2008; MUJOL; LORENZETTI, 2016; COSTA; LORENZETTI, 2018; LORENZETTI; COSTA, 2020). Por conseguinte, o fator principal do ensino, em geral, é possibilitar o desenvolvimento do senso crítico, para que os sujeitos sejam capazes de analisar, entender e buscar alternativas para os problemas e/ou situações encontradas, oportunizando a formação de cidadãos. Com base nisso, foi proposta a união da literatura infantojuvenil às atividades com contexto CTS, a fim de promover relações relevantes entre o ensino de Ciências/Química e o cotidiano dos alunos.

\section{O Ensino de Ciências a partir dos produtos domissanitários}

A ciência está em todos os lugares e pode ser descrita de diferentes modos. A alfabetização científica, como já exposto, ajuda na interpretação dessas informações de mundo, porém quando não se tem essa base de aprendizado consolidada, abre-se espaço para o chamado conhecimento popular. Esse tipo de conhecimento é uma das formas mais antigas e tradicionais de se passar informação através de gerações, mesmo que por vezes tais assuntos sejam abordados de forma superficial, incorretos ou baseados no achismo. O conhecimento comum é muito importante para o avanço social, pois possibilita propagar informações que foram extremamente importantes para a sobrevivência e manutenção das tradições de uma comunidade (NASCIBEM; VIVEIRO, 2015).

Porém, com o avanço da ciência e da tecnologia nas últimas décadas no campo social, o conhecimento científico tem-se popularizado, o que permitiu de certo modo a simplificação da linguagem científica, e possibilitou a discussão sobre assuntos antes dados como verdades sociais. Atualmente, a sociedade observa, sob olhar atento, ques- 
tões antes negligenciadas, como nos casos da utilização de substâncias cancerígenos em produtos comerciais, dos testes realizados em seres vivos, dos impactos causados por determinada substância no meio ambiente, entre outras questões ambientais, de saúde e sociais. Os produtos saneantes domissanitários também passaram por transformações, em função da mudança de alguns de seus compostos para atender a legislação vigente e aumentar a segurança de seu uso (ANVISA, 2003).

Em virtude da pandemia ocasionada pela disseminação do novo coronavírus, COVID 19, no Brasil, em 2020, cresceram acentuadamente o número de infecções registradas ocasionadas por produtos de limpeza, segundo a Nota Técnica (NT) 11/2020 divulgada pela Agência Nacional de Vigilância Sanitária (Anvisa), houve um aumento de $23,3 \%$, em comparação ao mesmo período do ano anterior (ANVISA, 2020). É possível supor que todos esses danos poderiam ser mitigados através de uma abordagem educativa sobre o manuseio seguro de produtos químicos, assim como ressaltar a importância da utilização dos Equipamentos de Proteção Individual (EPI). Com isso, a escola tem um papel central na orientação sobre a utilização, o manuseio e a armazenagem destes produtos, em que o ensino de ciências pode ser peça chave para uma abordagem adequada e condizente com os assuntos estudados nos anos iniciais, acentuando o papel dos alunos como disseminadores científicos em seus lares.

\section{Metodologia}

Foi realizada uma pesquisa com abordagem qualitativa, de natureza interpretativa, caracterizada, segundo Damiani (2012), como uma intervenção pedagógica. A sequência metodológica foi desenvolvida em três etapas, sendo realizada em dois ambientes, e em três dias. A primeira etapa se passou em um Simpósio, onde os alunos foram convidados para participarem como ouvintes de uma contação de história realizada pela contadora e autora do livro utilizado neste trabalho. As outras duas etapas, com duração aproximada de duas horas, foram aplicadas no ambiente escolar. No período das intervenções didáticas, os alunos cursavam o $4^{\circ}$ ano do ensino fundamental, em uma escola municipal, localizada no município de Duque de Caxias, Rio de Janeiro. A seguir, serão descritas detalhadamente as metodologias utilizadas no decorrer das atividades apresentadas. 


\section{1a etapa: Contação e apresentação da história}

O Simpósio Brasileiro de Educação Química (SIMPEQUI) ${ }^{1}$ realizado em 2018 abriu espaço em sua programação para receber 23 alunos da rede municipal caxiense, alocados no $4^{\circ}$ ano do ensino fundamental, para uma atividade inovadora. Eles participaram de uma contação de história do livro "A Luneta Mágica no Reino da Escuridão" (QUEIROZ, 2016), cujo objetivo era promover e incentivar o hábito da leitura pelos alunos. Além do fato de serem introduzidos em um ambiente incomum para seu cotidiano, tanto pelo translado da escola até o evento, que ocorreu em uma região completamente diferente a qual estão acostumados, como por estarem em contato com pesquisadores e cientistas de todos os lugares do país. Ao final da apresentação os alunos puderam fazer questionamentos para a autora sobre a história apresentada, sendo contemplados com um exemplar do livro em uma sessão de autógrafos e fotos.

\section{2a etapa: A "luneta mágica" e suas possibilidades pedagógicas}

A segunda etapa da atividade ocorreu na escola onde os alunos estavam matriculados. Para início, os pesquisadores pediram para que os estudantes relembrassem a história contada no SIMPEQUI, auxiliando-os durante a contação. Os alunos foram postos em uma roda de conversas para promover uma melhor discussão. Os estudantes, com o apoio dos pesquisadores, relembraram a história contando detalhes e expondo os sentimentos que surgiram no decorrer da contação, confirmando seu potencial pedagógico, uma vez que houve uma interação entre os alunos e a história. É importante ressaltar que esta etapa foi importante por dois motivos: o primeiro, por conta que dos 20 alunos presentes nesta etapa da intervenção, apenas 10 estiveram no SIMPEQUI; e o segundo, sondar se os alunos que estiveram no SIMPEQUI ainda se lembravam da história.

Durante as falas dos alunos acerca do livro, os pesquisadores salientaram a questão da luneta (artefato mais importante da história) e seu "poder mágico", que consentia em ver o que os corações gozavam. Após a contação, foi montada uma oficina para confecção de lunetas com diversos materiais alternativos, e assim, os alunos foram separados em dois grupos de quatro componentes, e quatro grupos de três componentes, em que cada grupo recebeu um kit com os materiais. Os pesqui- 
sadores demonstraram o passo a passo para que os alunos conseguissem montar suas próprias lunetas.

Para a confecção das lunetas os pesquisadores se basearam em um tutorial do YouTube intitulado: "Tutorial Luneta Teemo"2. Porém, alguns materiais foram adaptados em função do tempo disponível, sendo utilizados materiais alternativos e providos pelos pesquisadores, como: rolo de papelão, tesoura, fita adesiva e cola, além das garrafas PET que foram marcadas e cortadas adequadamente para confecção das lentes, como mostra a Figura 1. A priori, as atividades para esse dia foram com caráter humanístico, a fim de desenvolver o pensamento e a criatividade a partir das expressões artísticas, compartilhamento de saberes, além de se trabalhar as habilidades manuais com corte, recorte, colagem e desenhos.

Figura 1: Materiais alternativos para Oficina da Luneta

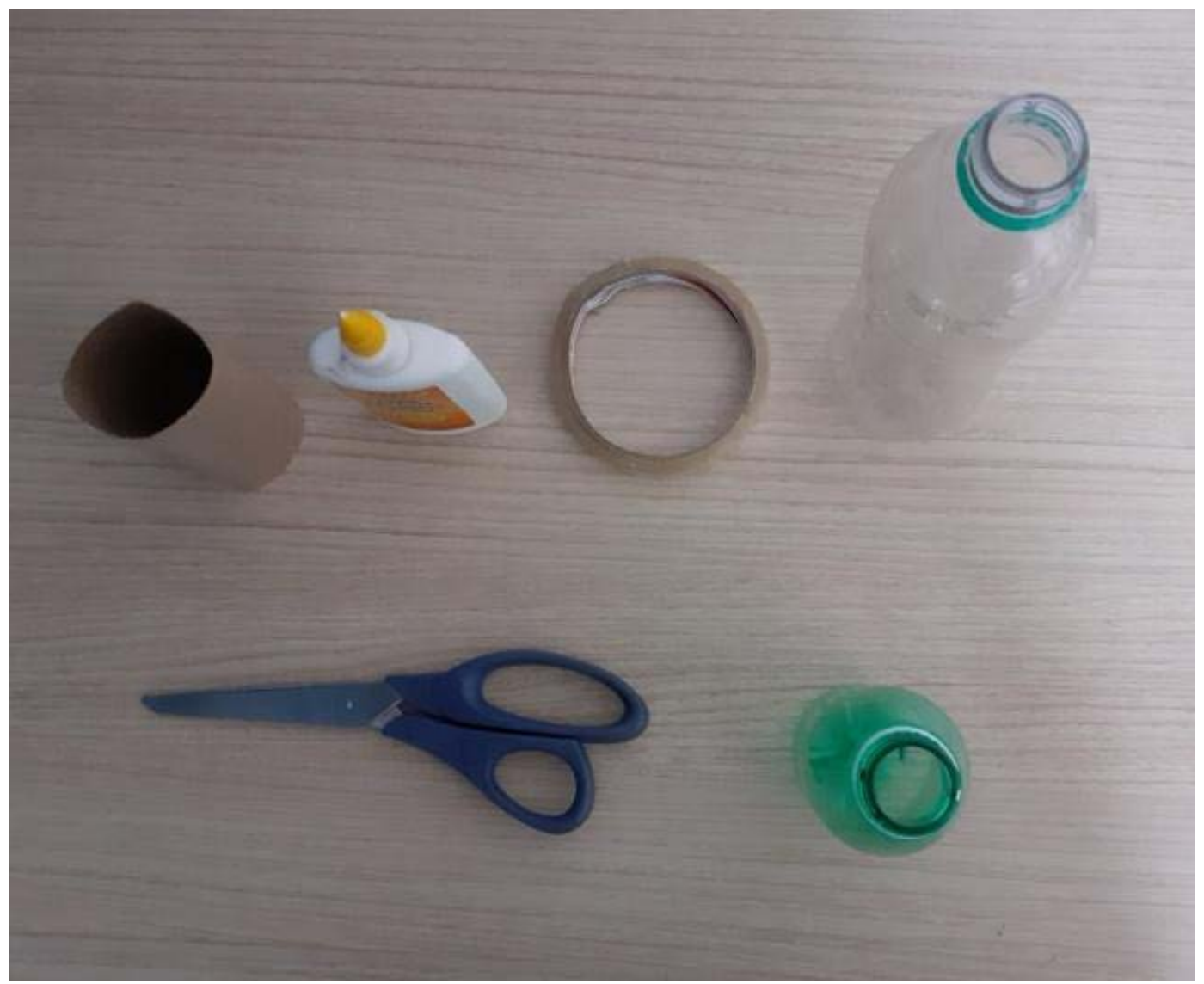

Fonte: Próprios autores. 
Após essa fase, todos os grupos finalizaram a confecção das lunetas, e o próximo momento pôde ser iniciado. As crianças foram lembradas do poder que a luneta mágica tinha na história, e então, foram indagadas sobre o que elas veriam ao utilizá-la, caso a luneta que elas tivessem construído possuísse o mesmo, ou similar, poder. As crianças utilizaram papel e lápis para representar, por meio de desenhos e escrita, seus anseios.

\section{$3^{a}$ etapa: Periculosidade de produtos saneantes domissanitários a partir da narrativa}

Os pesquisadores retornaram à escola para desenvolverem mais uma atividade em sala de aula, com a participação de 25 alunos, onde 15 haviam participado do SIMPEQUI. No início, os alunos foram organizados em um círculo pela sala, para uma roda de conversas. Esse método de participação coletiva foi escolhido por possibilitar a promoção de espaços de fala, escuta e maior interação entre as crianças (MELO; CRUZ, 2014).

O procedimento inicial foi bem similar ao executado na $2^{\mathrm{a}}$ etapa, em que os alunos relembraram a história do livro. Os estudantes recordaram muitos elementos do livro, inclusive o fato de um dos personagens ser cego. Após a releitura da história, foi retomada a causa da cegueira do rei, com o seguinte questionamento: "Por que será que o rei ficou cego?". Após algumas respostas, as crianças foram indagadas sobre o motivo pelo qual as pessoas, no mundo real, ficam cegas.

Os pesquisadores utilizaram-se desse fato da história para abordar os riscos decorrentes de produtos saneantes domissanitários, além de fazerem uma correlação com produtos alimentícios e segurança alimentar. Para auxiliar na interlocução e desenvoltura do tema, utilizaram uma apresentação em slides, por permitir a exibição de imagens e vídeos. Para salientar a periculosidade dos saneantes domissanitários, foi realizado um experimento demonstrativo, baseado no vídeo intitulado: "O violeta que desaparece (experiência de química)", disponibilizada pelo site Manual do Mundo ${ }^{3}$, a fim de salientar como não podemos confiar no aspecto visual dos produtos. Desta forma, utilizou-se água, vinagre, água oxigenada de 10 volumes $\left(\mathrm{H}_{2} \mathrm{O}_{2}\right)$ e uma solução de $5 \mathrm{~g} / \mathrm{L}$ de permanganato de potássio $\left(\mathrm{KMnO}_{4}\right)$. A partir das reações de oxirredução envolvendo o permanganato houveram similaridades dessas soluções com: suco de uva (solução de permanganato de potássio), refrigerantes de 
cola (reação da água oxigenada diretamente com o permanganato de potássio) e refrigerante de limão ou água gaseificada (reação da água oxigenada com a solução de permanganato de potássio e o vinagre). A etapa foi finalizada com a realização de uma gincana, relacionada com a atividade do dia.

Para facilitar a discussão dos resultados, neste texto, são utilizados os códigos "E" para referenciar os estudantes (por exemplo: "E1", referente a um determinado estudante e assim, consecutivamente). Os questionamentos estão representados através de códigos " $Q n$ ", sendo " $n$ " a ordem das perguntas.

\section{Resultados e discussão}

O livro "A Luneta Mágica no Reino da Escuridão" (QUEIROZ, 2016) foi selecionado a partir de uma atividade ocorrida em um Simpósio, onde os alunos participantes foram convidados para uma ação que envolvia a contação desta obra literária pela própria autora. Durante a apresentação, os alunos estiveram em contato com uma atividade inusitada para seu contexto, sendo expostos a uma apresentação interativa e harmoniosa.

A história inicia-se quando Lisa, a protagonista, encontra um livro mágico; e, ao abri-lo, depara-se com uma fada que a convida para uma aventura. Após aceitar o desafio, Lisa é apresentada a um reino mágico e antigo, onde recebe a explicação da fada, que o reino tem uma triste história que se iniciou há muitos anos atrás, em virtude da cegueira do rei, e que resultou na escuridão total do reino. Esta escuridão acabou minando aos poucos a felicidade dos habitantes que, depois de um tempo, tornaram-se tristes, simultaneamente com o desaparecimento do sol. Lisa descobre que a única maneira de trazer a luz de volta ao reino, seria através de uma luneta que tinha a capacidade de curar a cegueira do rei e que permitia ver o que os corações sentiam. Então, mesmo tendo medos e incertezas, ela decide encarar a viagem em busca da luneta dourada para salvar da tristeza todos que ali viviam. Nessa viagem ela conta com a colaboração de ajudantes valiosos para cumprir seu objetivo, além de correr alguns perigos iminentes (QUEIROZ, 2016).

Esse é o texto literário, usado na pesquisa, que apresenta um mundo rico em fantasia por meio de uma linguagem acessível e coerente com a faixa etária do público-alvo, além de demonstrar alguns valores que são muito importantes para o convívio social. Nele, os jovens podem ter oportunidade de imaginar e situar-se por 
meio das ilustrações bem feitas e coerentes com o texto proposto, sendo os desafios impostos aos personagens da fantasia, uma maneira de desenvolver a capacidade de resolver problemas no mundo real.

O livro apresenta características, que, segundo Blanco, Silva e Sobieszczanski (2015), permitem que o leitor possa viajar com as aventuras do mundo fantasioso, com possibilidades de conexões com o mundo real. Devido a esta conexão de mundos, algumas incógnitas permeiam a história, e por conta dos bolsistas do PIBIC, na época da pesquisa, cursarem Licenciatura em Química, vislumbrou-se a possibilidade em se trabalhar com temas químicos que estivessem presentes no convívio das crianças.

Questionar situações que poderiam passar despercebidas dentro da história, trazendo-as para o campo científico e associando às temáticas sociais, como por exemplo, o motivo da cegueira real, visa promover uma alfabetização científica. Buscaram-se discussões que pudessem trazer algumas relações de causa-consequência sobre 0 progresso da ciência e da tecnologia, desmistificando que os aparatos tecnológicos sempre são sinônimos de bem estar social. Conforme apontam Fabri e Silveira (2012), não podemos separar Ciência e Tecnologia da evolução do ser humano, pois ambas estão permeadas pelas ações de quem decide no processo de desenvolvimento.

\section{$1^{a}$ etapa}

O SIMPEQUI é destinado para pesquisadores na área da educação, sobretudo em educação química, entretanto, a edição de 2018 foi inusitada devido à participação de crianças no processo de obtenção de conhecimentos a partir da divulgação científica que o evento proporciona. Assim que os alunos chegaram ao espaço que estava acontecendo o evento, os pesquisadores observaram suas primeiras reações. Era perceptível a animação e curiosidade, tanto com o ambiente, como com os demais participantes, conforme relato da professora dizendo que: "era uma experiência inédita para todos".

O segundo momento de interação foi dos alunos com a contadora de histórias, Karina Queiroz. Neste instante, já em uma das salas do evento, a contadora pôde fazer a leitura da sua história, utilizando-se de fantoches e alternâncias de voz para cada personagem apresentado, além de usar tecidos que ilustravam os cenários da história e se alteravam de acordo com as dobras que ela fazia. Estes elementos co- 
laboraram com a apresentação repleta de expressões corporais, tornando a história mais dinâmica e interativa para os estudantes.

A desenvoltura evidenciada pela contação da história colabora com um importante papel na educação, principalmente na educação infantil, visto que os acessórios e a performance geram impactos audiovisuais, com apresentação e diálogo que remetem ao mundo fantasioso, de maneira que introduz as crianças ao universo literário, gerando interesse pela leitura. Estas histórias do gênero narrativo afetam o desenvolvimento social dos alunos, pois os valores e convivências que os diálogos transmitem começam a fazer parte dos seus saberes; tendo contato com novos vocábulos e assim amadurecem a linguagem, de modo que desenvolvem o cognitivo ao (re)produzirem os diálogos nas brincadeiras (MATEUS et al., 2013). A contação de histórias também afeta o desenvolvimento emocional dos estudantes pela expressividade da performance, permitindo-os lidar com questões como a tristeza, a perda, a felicidade, a insegurança, a tranquilidade e a ansiedade (MATEUS et al., 2013; ABRAMOVICH, 1989, p. 17, apud BLANCO et al., 2015, p. 121).

Ao final da contação, foi aberta uma rodada de perguntas para os alunos, e para os demais participantes presentes na sala. Os estudantes estavam envolvidos com a história, e curiosos para saberem além do que foi dito, mesmo com certa timidez, alguns alunos fizeram questionamentos permitindo assim, breves discussões. Um dos pontos abordados pelos alunos foi o motivo da cegueira do rei. A própria autora não tinha uma justificativa, e então, ela deixou para que eles explorassem a imaginação e propusessem o porquê da cegueira.

Para surpresa dos alunos, as experiências no Simpósio não haviam chegado ao fim. A autora se deslocou para a seção pertinente aos livros em que todos os alunos receberam um exemplar da história contada devidamente autografada, além de poderem tirar uma foto, eternizando assim, o momento incomum. Para finalizar a visita, as crianças ficaram livres para conhecer os diferentes ambientes do evento, além de interagirem com outros participantes, de modo que puderam voltar para a escola contando suas aventuras, observações e aprendizagens. Os pesquisadores tiveram perspicácia em identificar elementos interessantes da história (como a cegueira real) que poderiam ser explorados de forma diferente, possibilitando assim, a transição do conhecimento do mundo fantasioso para o mundo real, conforme as duas etapas seguintes. 


\section{$2^{a}$ etapa}

Os pesquisadores foram à escola para realizar a segunda etapa da intervenção em que fizeram a recontação da história e durante este processo, as crianças ressaltaram apreensão frente aos momentos de tensão vividos por Lisa, como o enredo e as vozes criadas para os personagens. Mas disseram que ficaram entusiasmados quando a narrativa se encaminhou para um desfecho positivo. Ao aproveitarem o momento de fala, as crianças expuseram as relações que estabeleceram com os outros participantes do Simpósio, indicando que conheceram cientistas e pesquisadores de diferentes estados do Brasil, e que foram estimulados a obterem informações e a compartilharem conhecimentos aprendidos em sala de aula e na vida, além de falarem sobre a forma carinhosa com a qual foram acolhidos.

Diante desse relato, ressalta-se como é importante proporcionar encontros em que estudantes da educação básica tenham a oportunidade de estarem presentes em um ambiente de divulgação científica. $\mathrm{O}$ contato com outra realidade possibilita-os criar pertencimento em um espaço antes não visto, o que, de certa, forma pode influenciá-los a estudarem e se dedicarem mais à escola, ampliando sua capacidade de aprendizado, tornando-os cidadãos melhores e possibilitando uma nova geração de cientistas. Logo, é importante o processo de disseminação do conhecimento, pois assim, novas perspectivas podem ser vislumbradas, frente a uma nova realidade. Conforme aborda Tavares (2014), o estado deve prover condições para que o estudante possa vislumbrar novas realidades, por isso o ensino está diretamente conectado a esse papel transformador.

[...] para esse pertencimento, estão implícitas condições fundamentais como saúde física e mental, autonomia, direito à informação, conhecimento de si e da sua cultura, auto-aceitação, oportunidade de conhecimento de outras culturas, enfim, uma gama de condições que são requisitos para que o indivíduo se sinta sujeito e capaz de participar voluntariamente dos processos de interação social (TAVARES, 2014, p. 198).

Após a contação da história e os relatos de experiências, os alunos falaram sobre o livro, e os pesquisadores salientaram a questão da "luneta mágica" e sua capacidade de ver o que os corações sentiam, dando início a oficina de lunetas. Com a estrutura do artefato pronta, as crianças expressaram interesse em enfeitar a luneta de papelão com papel, e assim ficaram livres para explorarem suas expressões artísticas. Cada grupo seguiu um método de roupagens, uns realizaram découpage ${ }^{4}$ 
nas suas lunetas com imagens desenhadas ou tiradas de revista, e outros escolheram colar desenhos que revestiam toda luneta. As crianças escolheram o melhor recurso para expressarem a identidade daquela unidade, com isso todas as lunetas ficaram diferentes proporcionando uma verdadeira variedade de imagens e cores.

Em virtude da falta de interação de alguns alunos no grupo do qual eram integrantes, ou incompatibilidade com o procedimento da confecção, os pesquisadores propuseram outro modelo de luneta para estas crianças. A nova forma de confecção exigia apenas duas garrafas PET (uma de 2 litros e outra de $230 \mathrm{~mL}$ ) e uma tesoura; a base da garrafa menor era cortada para encaixar e fixar a lente feita com a garrafa maior (Figura 2, A e B), resultando em uma luneta mais simplificada (Figura 2C), entretanto ainda possibilitando a expressão artística.

Figura 2: A) indicação do recorte da lente; B) indicação do recorte da base; C) luneta de garrafa PET

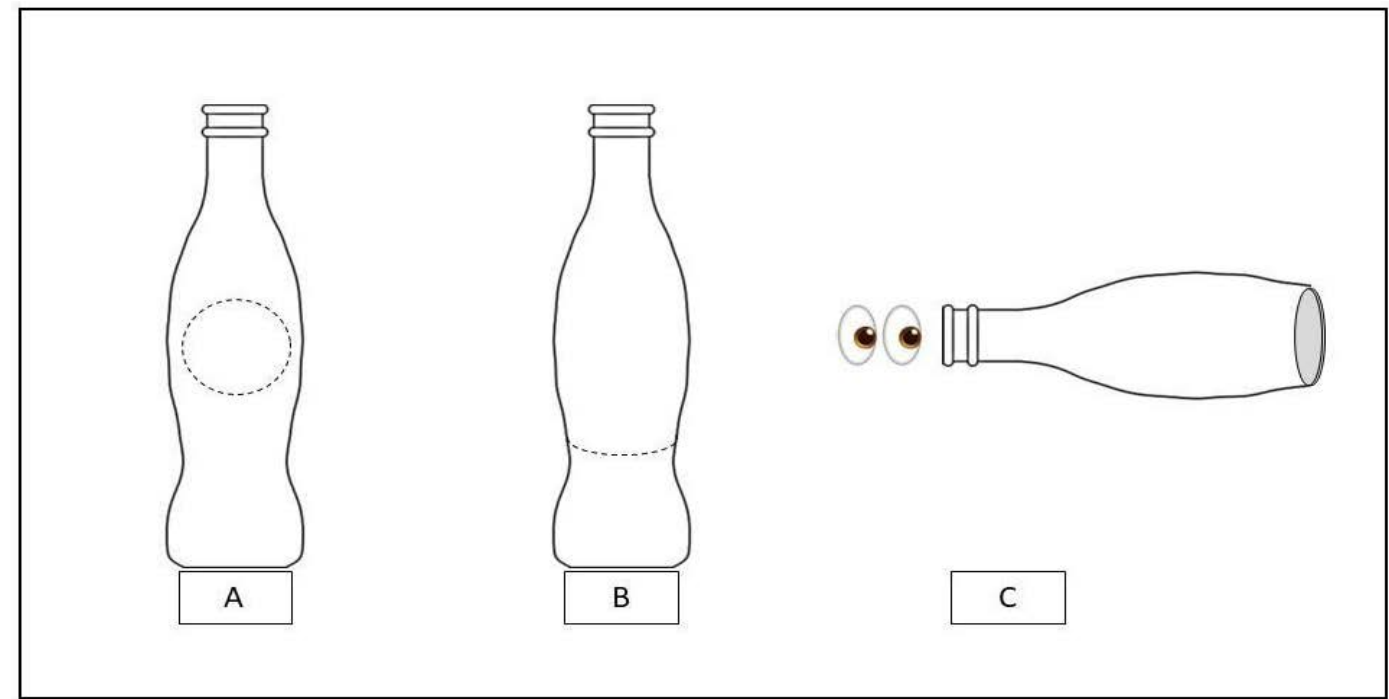

Fonte: Próprios autores.

A nova forma de fazer a luneta permitiu uma integração dos estudantes, uma vez que puderam pensar e executar outras decorações para luneta, e assim, livres para a exploração da criatividade. O preparo coletivo da luneta foi essencial para estabelecer uma conexão aluno-objeto, visto que a lenda da luneta explorada na história seria norteadora para a atividade seguinte. Quando terminaram a confecção do artefato, os alunos foram desafiados a utilizarem a imaginação, atribuindo às suas lunetas o mesmo poder do objeto na história. Deste modo, os estudantes 
expressaram por desenhos e textos o que desejavam observar através da luneta, como, por exemplo: o desejo que todas as famílias tivessem fartura de alimentos (desenho de uma família sentada à mesa farta); outro estudante relatou o desejo de conhecer o pai (desenho de uma figura masculina intitulada "esse é meu pai").

$3^{a}$ etapa

Devido aos questionamentos gerados com a contação da história no SIMPEQUI, foi notória a curiosidade dos alunos sobre a cegueira do rei. Como a autora não havia pensado nesse quesito, ela mesma propôs que as crianças especulassem o porquê da perda da visão. Naquele momento, os alunos não expuseram suas propostas, desta forma, os pesquisadores identificaram esta lacuna como norteadora de uma atividade com discussões envolvendo conhecimentos químicos, em vista da formação dos mesmos.

Para isso, os pesquisadores voltaram à escola para a terceira e última etapa da intervenção, que contou, ao todo, com 25 alunos, sendo que a releitura da história da luneta mágica foi a precursora das atividades do dia. A releitura foi utilizada para enfatizar alguns detalhes, uma vez que os alunos já estavam familiarizados com a história, e ao chegar ao final, os pesquisadores conduziram para o primeiro questionamento:

Q1 - "Por que será que o rei ficou cego?"

No primeiro momento os alunos disseram que poderia ser maldição ou algo relacionado com magia, tendo em vista do contexto da história. Entretanto, os pesquisadores fizeram outro questionamento:

$\mathrm{Q} 2$ - "E se fosse no mundo real, o que poderia ter causado essa doença?"

Em seguida, eles responderam que a cegueira poderia ser causada por motivos que se alternavam entre: velhice, doenças, produtos químicos e antena de pipa. Depois de muitas possíveis causas, uma aluna comentou sobre o risco em se manusear alguns produtos e eventualmente passar a mão no rosto, principalmente na região dos olhos, e isso poderia causar cegueira. A partir desse comentário, a discussão sobre a periculosidade dos produtos químicos foi iniciada.

Os licenciandos-pesquisadores, baseados nos trabalhos de Pires, Deccache-Maia e Messeder (2016), elaboraram uma apresentação em slides, com intuito de demons- 
trar para as crianças os riscos em se armazenar produtos sem rótulos, com rótulos trocados, e também o perigo em se realizar misturas de produtos diferentes. Utilizando-se de imagens disponíveis na internet, que comparavam as semelhanças entre algumas embalagens de produtos de limpeza e alimentícios, deu-se início ao debate.

A primeira imagem questionadora foi de garrafas PET proveniente de refrigerantes que continham alguns líquidos coloridos (em geral desinfetantes). Cabe ressaltar que as crianças se familiarizaram com esses produtos, em virtude de serem livremente comercializados pelas vizinhanças da escola. Ao despertar sobre o risco à saúde dos produtos de limpeza, especialmente os caseiros, os alunos relataram as experiências de parentes ou conhecidos que sofreram intoxicação por ingestão de tais produtos, como a estudante E1 que relatou a ingestão de cloro por sua mãe e a estudante E2 que relatou que seu responsável colocou uma garrafa (reutilizada indevidamente) de cloro na geladeira pensando ser suco. O momento de fala dos alunos oportunizou uma aprendizagem coletiva, em que eles perceberam, analisaram e tiraram suas conclusões frente às atitudes erradas dos seus responsáveis, de modo que essa experiência serviu como aprendizado sobre comportamentos errôneos, muitas das vezes praticados no cotidiano das pessoas. A partir desses depoimentos, os pesquisadores fizeram uma nova pergunta:

Q3 - “Como fazer para não se cometer os mesmos erros?”.

Durante o diálogo mediado, os alunos foram levados a pensarem em uma solução do problema como, o mau armazenamento de alguns produtos e a falta de rotulagem apropriada. E assim, indicaram que é importante se ter uma rotulagem adequada assim que o produto chega à residência, seja com o rótulo feito na embalagem, por meio de uma caneta marcador de retroprojetor, ou até mesmo um rótulo feito de papel com as informações mais pertinentes daquele produto, como: nome, validade e riscos à saúde.

A periculosidade dos produtos químicos foi ressaltada inicialmente contemplando o aspecto visual. Os pesquisadores aproveitaram para mostrar que embalagens coloridas poderiam se tornar chamativas aos olhos infantis atiçando a curiosidade, o que poderia causar sérios problemas. Por isso, uma parte da apresentação teve por objetivo, advertir sobre os riscos químicos alertando sobre cheiro enganoso proveniente dos aromatizantes que simulam algo comestível, e a aparência que pode ser confundida com alimentos. 
Para isso, os pesquisadores mostraram imagens ressaltando grandes semelhanças entre produtos de limpeza e inseticidas com produtos alimentícios, que indicaram os riscos que poderiam estar presentes em seus domicílios e que exigem atenção. Os estudantes não só identificaram o perigo como novamente contaram histórias que confirmavam a necessidade do alerta, como o caso da estudante E3 que relatou que seu primo, de pouco mais de um ano, quase ingeriu uma pastilha de inseticida (pedras de naftalina) - que estava sendo mostrado na apresentação ao ser comparado com uma goma de mascar - e ela interveio antes que ele pudesse colocar na boca. Outros alunos relataram histórias parecidas, em que o estudante E4 confundiu "chumbinho" com comida de pássaros e E5 falou da semelhança da cola e tinta branca.

Após salientar os perigos em virtude das semelhanças, ressaltaram-se também os riscos com o manuseio, em que uma conduta imprudente, ao misturar materiais de limpeza desconhecidos, poderia ter consequências irreparáveis à vida. Os pesquisadores mostraram os efeitos do uso inadequado de alguns produtos através de imagens que envolvessem acidentes ou lesões, ocasionados especialmente por produtos de limpeza, em função do manuseio incorreto. Com isso, ressaltou-se a importância de utilizar luvas e outros equipamentos de proteção individual, além de se manter o local arejado.

Durante a apresentação, outras experiências foram compartilhadas, como por exemplo, os perigos em se utilizar o cloro vendido sem certificação e/ou a água sanitária para a limpeza de ambientes fechados, como é o caso da professora que relatou ter sofrido um mal-estar ao utilizar estes produtos para limpeza de um banheiro todo fechado. Surgiram dúvidas entre os estudantes sobre como identificar a periculosidade de um produto, e assim, foi conveniente apresentar os pictogramas e como fazer sua leitura, indicando suas localizações nas embalagens.

A intervenção teve continuidade com um experimento demonstrativo para destacar o perigo que há em confiar somente na aparência dos produtos, por isso os pesquisadores utilizaram um experimento com aspectos visuais similares a bebidas conhecidas pelas crianças: suco de uva, refrigerante de cola, refrigerante de limão/ água gaseificada. Os alunos estavam cientes que a substância que observavam naquele momento eram impróprios para consumo, salientando novamente como devem ficar desconfiados e ter cuidado com os materiais que não estão rotulados. 
Para finalizar a intervenção, foi realizada uma gincana com os temas abordados na apresentação, sendo as crianças divididas em dois grupos. Assim, cada grupo teve a oportunidade de responder os questionamentos anunciados pelos pesquisadores, sendo necessárias justificativas e com um tempo cronometrado para as respostas. Como por exemplo:

Q4 - "Qual o jeito mais certo de identificar um produto sem rótulo?"

E1: "Depois de saber o que é: botar um rótulo para poder identificar e deixar no alto fora do alcance das crianças menores".

Através dessa, e outras respostas, os pesquisadores perceberam que ao final da intervenção as crianças haviam entendido a importância em se rotular adequadamente os produtos, uma vez que para responder esse questionamento diversos alunos falaram sobre "colocar nome" ou "colocar rótulo", de forma que foi ressaltada a importância em buscarem ajuda dos seus responsáveis, já que eles provavelmente saberão executar o procedimento, conforme a fala da aluna E1, que foi frisado durante toda a intervenção.

Após algumas perguntas e respostas, foi possível notar outro olhar sobre situações do cotidiano, em que os estudantes começaram a se atentar e a identificar outros possíveis cuidados que se deveriam ter com os produtos químicos presentes em casa. As crianças aproveitaram o fim da intervenção para fazer questionamentos e saber quando seria a próxima atividade com aquele caráter, ficando explícito o desejo por fazer ciência, como a estudante E1 questionou: "Na próxima aula vamos fazer química?".

A construção dos conhecimentos estabelecidos e construídos durante a discussão foi planejada, com intuito, de mostrar para as crianças os perigos em se utilizar/ armazenar produtos sem ou mal rotulados, dos produtos que apresentam aromatizantes alimentícios, dos produtos que aparentam alimentos e também ressaltar o manuseio e o armazenamento inadequado de algumas substâncias, além de serem apresentados os pictogramas mais comuns presentes nos produtos domésticos.

A partir das atividades realizadas, espera-se que os estudantes possam exercer seu potencial de divulgadores científicos, visto que ao se falar da ingestão de produtos tóxicos, e do manuseio inadequado dos produtos de limpeza, em situações cotidianas parecidas com as retratadas nessa atividade, eles poderão compartilhar os saberes 
aprendidos em sala de aula, e assim, mudar sua realidade, positivamente, por meio dos seus conhecimentos científicos.

\section{Considerações Finais}

Proporcionar momentos, em que os estudantes são levados a ambientes diferentes dos quais estão acostumados, gerou um encantamento e um pertencimento dos alunos a esses lugares, pois além de conhecerem outra realidade, houve um bom acolhimento por parte dos outros participantes do Simpósio, ouvindo-os e se relacionando de forma igualitária. Com isso, possibilita-se o surgimento de novas perspectivas frente às formas de se aprender, de modo que podem servir como fonte de inspiração para alterarem a sua própria realidade.

A oficina da luneta permitiu a exploração das habilidades motoras, incentivando a criatividade e possibilitando abarcar discussões humanísticas ao explorar os desejos infantis. Este momento possibilitou um maior entendimento da realidade dos alunos, e assim, a partir da práxis pedagógica, o professor é capaz de propor aulas mais significativas para aquele público.

Os alunos mostraram entusiasmo e interesse no tema sobre a periculosidade dos produtos químicos, quando se tornaram interlocutores da apresentação, por ser uma atividade dialógica com a exposição de experiências reais e vivenciadas por eles. Nesta etapa, promover a alfabetização científica foi crucial para aqueles estudantes, para que pudessem reconhecer os riscos que encontramos no cotidiano, tendo assim, a sua criticidade estimulada, o que de certa forma colabora com a formação de cidadãos aptos para alterarem a sua realidade.

Os objetivos da intervenção foram contemplados, visto que foi perceptível a mudança de discurso das crianças, pois através dos diálogos, saberes foram produzidos de forma que passaram a atentar-se para a periculosidade dos produtos químicos, tendo uma visão mais holística e crítica do ambiente em que vivem. Visto que mesmo ainda sendo estudantes do primeiro segmento, eles reconheceram que podem atuar como divulgadores científicos, sendo possível identificar o anseio por obter conhecimento e divulgá-lo em suas casas o que aprenderam, sejam por falas ou atitudes. 


\section{Storytelling as a strategy for teaching science}

\section{Abstract}

The article brings discussions about a pedagogical intervention, proposed in a project of the Programa Institucional de Bolsas de Iniciação Científica (PIBIC), which aimed to promote an association between children's stories and science education. The activities were based on the Science, Technology and Society (STS) approach, based on a qualitative study, classified as intervention research. The guiding theme of the research was based on a storytelling, for 23 children from the 4th year of elementary school in the municipal network of the municipality of Duque de Caxias (RJ). Then, didactic strategies were developed in the classroom, promoting the STS approach, through narratives of children's literature, which provided a workshop for making telescopes with humanistic discussions and an activity that evidenced chemical risks of sanitizing products. Thus, the research enabled the exploration of new perspectives for the scientific literacy of children in this stage of schooling. The results pointed to the possibilities of combining children's and youth stories and science teaching, promoting humanistic and socio-scientific discussions, bringing scientific knowledge closer to the real world.

Keywords: Storytelling; Science teaching; Elementary School.

\section{Agradecimentos}

Este trabalho foi realizado com suporte financeiro da Fundação Carlos Chagas Filho de Amparo à Pesquisa do Estado do Rio de Janeiro - FAPERJ (Bolsa de Auxílio a Projeto de Pesquisa, APQ1, no 210.327/2019).

\section{Notas}

1 O SIMPEQUI é um evento anual, itinerante pelo país, organizado pela Associação Brasileira de Química (ABQ), destinado às discussões sobre educação química (http://www.abq.org.br/simpequi/. Acessada em 02 nov. 2020).

2 Vídeo disponível em: https:/www.youtube.com/watch?v=nqdQy61_yFk. Acesso em: 03 jul. 2020.

3 O violeta que desaparece (experiência de química). Manual do Mundo, 2011. Disponível em: https:// manualdomundo.uol.com.br/2011/11/o-violeta-que-desaparece-experiencia-de-quimica/. Acesso em: 26 de mar. de 2020.

4 Técnica artesanal que consiste no recorte de gravuras de papel (guardanapos, papel, etc.) para revestir superfícies de objetos em madeira, metal, vidro ou tecido. Fonte: https://www.infopedia.pt/dicionarios/ lingua-portuguesa/d\%C3\%A9coupage. Acesso em: 03 jul. 2020. 


\section{Referências}

ANVISA - AGÊNCIA DE VIGILÂNCIA SANITÁRIA. Nota Técnica no 11/2020. 2020. https:// www.gov.br/anvisa/pt-br/assuntos/noticias-anvisa/2020/alerta-cresce-intoxicacao-por-produtos-de-limpeza. Acesso em: 25 out. 2020.

ANVISA - AGÊNCIA DE VIGILÂNCIA SANITÁRIA. Resolução - RDC no 225, de 25 de agosto de 2003. Institui o modelo do Certificado de Boas Práticas de Fabricação para Saneantes Domissanitários e Modelo de Formulário de Petição. Brasília: ANVISA, 2003. Disponível em: https://www.normasbrasil.com.br/norma/resolucao-225-2003_99041.html\#: :text=Institui\%20 o\%20modelo\%20do\%20Certificado,que\%20lhe\%20confere\%20o\%20art. Acesso em: 25 out. 2020.

ARANA, Alba Regina de Azevedo A; KLEBIS, Augusta Boa Sorte Oliveira. A importância do incentivo à leitura para o processo de formação do aluno. Encontro Nacional de Educação - EDUCERE, v.12, 2015, Anais [...] Curitiba/PR: Editora Universitária Champagnat, 2015.

BLANCO, Vanessa Just; SILVA, William Pohlmann Maria; SOBIESZCZANSKI, Miriam. A literatura infantojuvenil sob a perspectiva da psicologia. Educação, Ciência e Cultura, Canoas, v. 20 , n. 2 , p. $113-128,2015$.

BRANDÃO, Ana Carolina Perrusi; ROSA, Ester Calland de Souza (org.). Ler e escrever na educação infantil: discutindo práticas pedagógicas. 2 ed. Belo Horizonte: Autêntica Editora, 2011.

BRASIL. Secretaria de Educação Fundamental. Parâmetros curriculares nacionais: introdução aos parâmetros curriculares nacionais / Secretaria de Educação Fundamental. Brasília: MEC/SEF, 1997. Disponível em: http://portal.mec.gov.br/seb/arquivos/pdf/livro01.pdf. Acessado em: 10 de jan. de 2020.

BRASIL. Ministério da Educação. Base Nacional Comum Curricular. Brasília, 2017. Disponível em: http://basenacionalcomum.mec.gov.br/images/BNCC_20dez_site.pdf. Acessado em: 10 de jan. de 2020 .

CHASSOT, Attico. Alfabetização científica: uma possibilidade para a inclusão social. Revista Brasileira de Educação, n. 22, p. 89-100, 2003.

COSTA, Ellen Moreira; LORENZETTI, Leonir. Disseminação da alfabetização científica nos anos finais do ensino fundamental: da produção acadêmica aos livros didáticos. Revista de Ensino de Biologia da SBEnBio, v. 11, n. 1, p. 88-104, 2018.

DAMIANI, Magda Floriana. Sobre pesquisas do tipo intervenção. UNICAMP, Campinas, 2012. Disponível em: <http://endipe.pro.br/ebooks-2012/2345b.pdf >. Acesso em: 12 de out. 2020.

FABRI, Fabiana; SILVEIRA, Rosemari Monteiro Castilho Foggiatto. Alfabetização científica e tecnológica nos anos iniciais a partir do tema lixo tecnológico. Revista Brasileira de Ensino de Ciência e Tecnologia, v. 5, 2012. Acesso em 09 jan. 2020, <https://periodicos.utfpr.edu.br/ rbect/article/view/1264>.

$\mathrm{KOCH}$, Ingedore Villaça; ELIAS, Vanda Maria. Ler e compreender os sentidos do texto. São Paulo: Contexto. 2006.

LORENZETTI, Leonir; COSTA, Ellen Moreira da. A promoção da alfabetização científica nos anos finais do ensino fundamental por meio de uma sequência didática sobre crustáceos. Revista Brasileira de Ensino de Ciências e Matemática, v. 3, n. 1, p.11-47, 2020. 
LORENZETTI, Leonir; DELIZOICOV, Demétrio. Alfabetização científica no contexto das séries iniciais. Ensaio - Pesquisa em educação em Ciências, v. 3, n. 1, p. 1-17, 2001.

MATEUS, Ana do Nascimento Biluca. et al. A importância da contação de história como prática educativa na educação infantil. Pedagogia em Ação. Minas Gerais, v. 5, n. 1, p. 54-69, 2013.

MELO, Marcia Cristina Henares de; CRUZ, Gilmar de Carvalho. Roda de conversa: uma proposta metodológica para a construção de um espaço dialógico. Imagens da Educação, v. 4, n. 2, 2014.

MESSIAS, Alessandro da Silva. Marcas enunciativo-discursivas nas histórias em quadrinhos (HQs): uma proposta de análise de texto como discurso. Rio de Janeiro: UFRJ, 2006. Dissertação (Mestrado em Letras Vernáculas) - Faculdade de Letras, Universidade Federal do Rio de Janeiro, 2006.

MUJOL, Sandra Godoi Maestrelli; LORENZETTI, Leonir. A abordagem Ciência, Tecnologia e Sociedade nos anos iniciais do ensino fundamental. In: Simpósio Nacional de Ensino de Ciência e Tecnologia, v. 4, 2016, Anais [...]. Ponta Grossa: UTFPR, 2016.

MUNDIM, Juliana Viégas; SANTOS, Wildson Luis Pereira dos. Ensino de ciências no ensino fundamental por meio de temas sociocientíficos: análise de uma prática pedagógica com vista à superação do ensino disciplinar. Ciência \& Educação (Bauru), v. 18, n. 4, p. 787-802, 2012.

NASCIBEM, Fábio Gabriel; VIVEIRO, Alessandra Aparecida. Para além do conhecimento científico: a importância dos saberes populares para o ensino de ciências. Revista Interacções, n. 39, p. 285-295, 2015.

OLIVEIRA, Denise Ana Augusta dos Santos; MESSEDER, Jorge Cardoso. Da narrativa literária à produção textual coletiva: remontando temas químicos no Ensino Fundamental. Revista Thema, v. 14, n. 2, p. 137-150, 2017.

PIRES, Romulo de Oliveira, DECCACHE-MAIA, Eline, MESSEDER, Jorge Cardoso. Usando o tema riscos químicos em espaços não formais de ensino. Ensino, Saúde e Ambiente, v. 9, n. 3, p. 283-296, 2016.

QUEIROZ, Karina. A luneta mágica no reino da escuridão. Rio de Janeiro: Brinque Ler, 2016.

ROEDEL, Tatiana. A Importância da Leitura e da Literatura no Ensino da Matemática. I Encontro Brasileiro de Estudantes de Pós-Graduação em Educação Matemática, v. 20, 2016, Curitiba. Anais [...]. Curitiba:UFPR, 2016.

SANTOS, Wildson Luis Pereira dos; SCHNETZLER, R. P. Função Social: o que significa ensino de Química para formar o cidadão? Química Nova na Escola, n. 4, p. 28-34, 1996.

SASSERON, Lúcia Helena; CARVALHO, Anna Maria Pessoa. Almejando a Alfabetização Científica no ensino fundamental: A proposição e a procura de indicadores do processo. Revista Investigações em Ensino de Ciências, v. 13, n. 3, p. 333-352, 2008.

SASSERON, Lúcia Helena; CARVALHO, Anna Maria Pessoa. Uma análise de referenciais teóricos sobre a estrutura do argumento para estudos de argumentação no ensino de ciências. Ensaio Pesquisa em Educação em Ciências (Belo Horizonte), v. 13, n. 3, p. 243-262, 2011.

SILVA, Carmem Luci Costa. Experiências de significação na linguagem: enunciação e ensino de língua materna. Signo, v. 41, n. Especial, p. 20-28, 2016.

TAVARES, Rosana Carneiro. O sentimento de pertencimento social como um direito básico e universal. Cadernos de Pesquisa Interdisciplinar em Ciências Humanas, v. 15, n. 106, p. 179-201, 2014. 
TEIXEIRA, Francimar Martins. Alfabetização científica: questões para reflexão. Ciência \& Educação (Bauru), v. 19, n. 4, p. 795-809, 2013.

ZÔMPERO, Andreia Freitas; LABURÚ, Carlos Eduardo. Atividades investigativas no ensino de ciências: aspectos históricos e diferentes abordagens. Ensaio Pesquisa em Educação em Ciências (Belo Horizonte), v. 13, n. 3, p. 67-80, 2011. 